\title{
Models for Virtual Learning
}

\author{
Vijay Kanabar \\ Boston University, USA
}

kanabar@bu.edu

\begin{abstract}
The American Council on Education estimates that 85\% of traditional colleges and universities offers distance-accessible courses. Boston University has been an early player in this arena, and in this paper we synthesize two models for virtual learning on the basis of actual courses that took place. Also we focus on the authors experience with communicating at a distance in the context of credit and non-credit courses.
\end{abstract}

Keywords. Virtual Learning, Distance Education, Communicating at a Distance

\section{Introduction}

The Metropolitan College of Boston University has been a leader in New England in serving the needs of the parttime and continuing education students. This leadership has started manifesting into distance education as well. We have started the process of adapting fully to what is happening around the world-a permanent shift in the delivery of education through out the world. In this paper we identify two models for distance education and describe our experience within the context of this model.

An important reason why students enroll in distance courses is to improve job skills. Both corporations in the real world and universities have begun to zero in on this non-credit training market. Therefore any discussion in this paper is relevant to both credit and non-credit courses.

\section{The Model}

With the popularity of WWW and web-based instruction (WBI), a new model to deliver courses on the Internet has emerged. WBI allows us to effectively administer course material, tutorials and quizzes, or to communicate with the students. More important we have a powerful mechanism to teach the class-using the web for communication with

Material published as part of this proceedings, either on-line or in print, is copyrighted by the author with permission granted to the publisher of Informing Science for this printing. Permission to make digital or paper copy of part or all of these works for personal or classroom use is granted without fee provided that the copies are not made or distributed for profit or commercial advantage AND that copies 1) bear this notice in full and 2) give the full citation on the first page. It is permissible to abstract these works so long as credit is given. To copy in all other cases or to republish or to post on a server or to redistribute to lists requires specific permission from the author. the student. Web technology has matured significantly today to allow voice and graphics including video to be effectively transmitted at a distance.

With the above a clear model has emerged for developing content and presenting content. Our research reveals that the distance education project scope can be defined in two dimensions - place and time-and within the context of the following two attributes-work, and technology

(1) The Work: Place and Time Dimension

(2) The Technology: Place and Time Dimension

\section{The Work: Place and Time Dimension}

Figure 1 illustrates this model. There are several components that can be studied:

- same place and same time

- same place but different time

- different place but same time, and

- different time and different place. 


\begin{tabular}{|l|l|l|}
\hline \multicolumn{1}{|c|}{ Time } & Same & Different \\
\hline Place & $\begin{array}{l}\text { Face to face } \\
\text { instruction } \\
\text { (synchronous) }\end{array}$ & $\begin{array}{l}\text { Not face-to- } \\
\text { face } \\
\text { Asynchronous } \\
\text { (Eg., Lab) }\end{array}$ \\
\hline Different & $\begin{array}{l}\text { Distance } \\
\text { Education } \\
\text { (synchronous) }\end{array}$ & $\begin{array}{l}\text { Distance } \\
\text { Education } \\
\text { (asynchronous) }\end{array}$ \\
\hline
\end{tabular}

Figure 1: The Work

Face-to-Face: This strategy needs no introduction. We have been involved with this aspect of education from the very beginning. The plus points with this are that students have the human touch. Many students need this aspect and we quote (Moore, 96): "The absence of the "father figure" or "mother figure" to take care of them is disconcerting for some students." While this appears to be good at face value research also reveals that having access to the mentor also prevents the students from working harder. Research reveals such conclusions as well (Moore, 96) "Most students are able to cope with problems, and most students actually enjoy taking responsibility for solving their own problems. This is obviously harder work than letting a teacher do it."

Not Face-to-Face: Why should we consider this dimension? Here we have a rare scenario; the student is sick or away on business; the professor teaches the class at the scheduled time and leaves. Distance education technology provides us an excellent opportunity to address this situation. The author of this paper has provided a video and audio recording of his lecture on two occasions for such purposes. A digital camera was brought to the computer lab. A student was asked to assist with the recording. Subsequently the recording was digitized and published on the web and the absent students were requested to go to the Internet and review the recording. It must be stated that the quality of such ad-hoc recording is poor. The instructor only focuses on his full time students, and walks around and away from the view of the camera frequently. Also irrelevant questions and answers are recorded. Nevertheless, the students who subsequently came to the lab to use the recording were satisfied that they did not miss something important. They watch the video recording at their convenience, do the labs independently (without any assistance from the instructor) and leave at their convenience.
Synchronous Distance Education: Boston University's has been involved with synchronous distance education for several years. The earlier attempts involved using Picture Tel where live students are assembled in one classroom with the instructor and others are assembled in a remote campus. The students at the remote campus are happy to be part of the course and do their best to participate with the students in the live campus.

From the perspective of the instructor it was incredibly frustrating to manage the course. The Picture Tel technology was buggy and telecommunication was unreliable. Since we were given no student/camera-person to record the instructor and move the camera around (as the instructor went back and forth between the blackboard and the computer), the lectures were of poor quality. Student evaluations from the distance campus were lower than the student evaluations from the live campus. Also students at the live campus found the distance education students to be a distraction. While this strategy of teaching can be classified as "Live Synchronous Distance Education", let us compare this strategy with the "Non-live".

\section{Live Synchronous Distance Education Vs. Non-Live Syn-} chronous Distance Education: This involves teaching technology topics via WBI and proprietary broadcasting tools from companies such as Centra or Interwise Inc. Unlike Picture Tel-there are no students present in the classroom when the seminar is being broadcasted. The plus point with this strategy is that the professor does not have to deal with the local audience and focuses on the distance audience exclusively. The experience and evaluation with non-live teaching were better for both the instructor and the student. What are the advantages with this approach? From the perspective of the student this strategy brings the collaborative, interactive environment of a classroom right to their desktop--complete with the instructor. They don't have to endure traffic jams on their way to school. From the perspective of the university (and marketing) there are no geographic boundaries; the potential of seeing an increase in enrollment exists.

Asynchronous Distance Education: This last dimension is probably what distance education is all about. This is evident from the formal definition of the term distance education by several authorities. IDDA (IDDA, 99) states: "Distance education is a process to create and provide access to learning when the source of information and learners are separated by time and distance." To be classified as true distance education the university should be able to deliver both at a distance and across different time zones. The author's first experience with this came about in fall 


\section{Models for Virtual Learning}

of 2000 when the computer science department developed a Graduate Certificate program in Databases and Client/Server for the employees of Keane, Inc. - a wellestablished consulting company in the field of information technology (IT), with offices in Massachusetts, New Hampshire, Maine and Vermont. This led to the following design choices (Zlateva, 2001):

(i) A lecture format that is a blend of face to face, on-site lectures and web lectures featuring streaming audio and video, synchronized with a slide presentation, graphics, and animation. Courses follow a 12-week format, with weekly web lectures and one face-to-face lecture each month to provide for synchronicity.

(ii) Weekly homework assignments, with either examinations or course projects.

(iii) Weekly on-line office hours through a chat facility.

(iv) Course web site, providing

- additional forms of communication: chat, threaded discussion, class e-mail,

- teaching materials: syllabus, web-lectures, slides, exercise problems and solutions, links to on-line resources

- homework submission and grade management.

To reduce risks of distance education we took a blended approach to delivery of this program. Every fourth class was offered live at a site close to all students. In this case the Holiday Inn in Portsmouth was used as the meeting for the seminar. The quality of the course material was very high. Figure 2 illustrates a screen from one of the recordings. We see the instructor delivering the seminar in a video window on the left and the slides on the right.

The only constraint with this strategy is that students had to have a high bandwidth cable or DSL connection or had to use the T1 connection from work in order to listen to the lectures. Subsequently, the author improvised on this initial strategy by allowing both a voice only lecture and a voice plus video lecture. This strategy alleviated the bandwidth concerns that some students had.

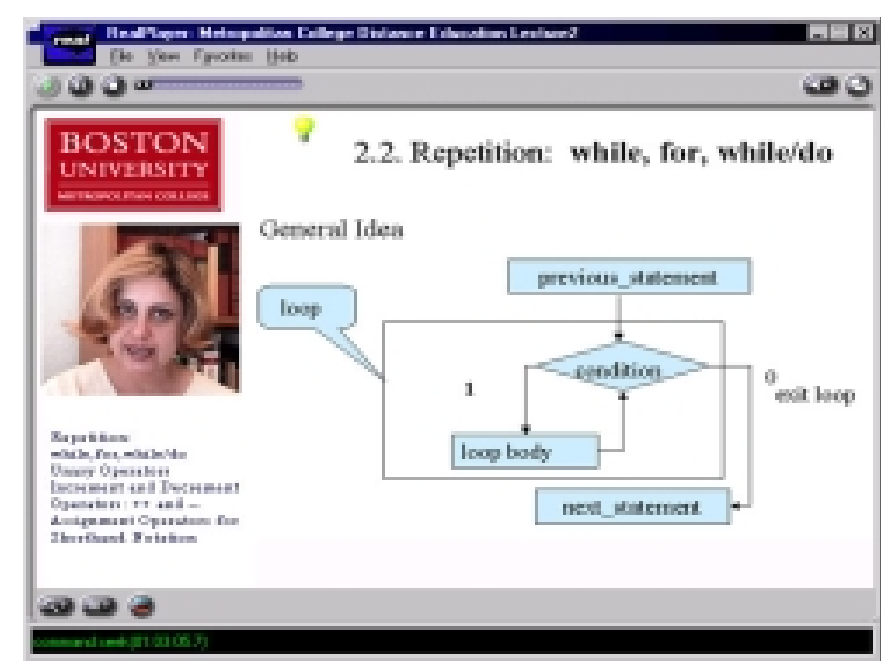

Figure 2: Different Place, Different Time

From the comments collected by the instructor the following aspects are satisfying about distance education.

(1) Focus is on learning by the student and not on teaching by the instructor. Students are happy eventually as they have to taken more responsibility for their own learning

(2) Not having to commute to school or college

(3) Access to current material that is well blended with content available for free in the Internet.

(4) Taking the seminars whenever the student has spare time and he/she is not constrained by fixed slots of classroom delivery.

(5) Reusable resource. Traditional classroom lectures are a one-shot deal. If a student cannot hear the instructor clearly or the mind wanders away a lot of content is lost. Distance education produces reusable seminars. Such seminars also allow the student to zero in on some difficult concepts over and over again.

The limitations on the basis of comments from my students all seem to stem from technology. They want better support for technology and administration of the course (this is true from the perspective of the instructor as well).

(1) Guidance/counseling: At the early stages it is registration, getting logged on to electronic tools, getting university id and accounts. (All of these were huge challenges especially at Boston University, 
which has very strict policy of on campus physical validation of ID.)

(2) Administrative assistance: Where is the web page? Where is the course? How do I log on? Why is my password not working? My computer is not working.... what do I do?

(3) Interaction: Students expect higher degree of interaction using tools or even over email and phone. This is a major limitation as the instructor gets swamped with emails. One of the best recommendations from the perspective of the instructor is to create a unique yahoo email account for each distance education course you teach. This way you can focus on the emails from the students and interact with them quickly.

From the perspective of the professor, distance education, can be a frustrating lonely experience. The author has been delivering live seminars for 22 years and could not easily adapt to teaching to the camera for 3 hours (without going insane). Also, the passion and "story-telling" was missing in the video recordings. This according to researchers is a valuable component of distance education. Distance education instructors must deliver courses with the same passion and tell the same "stories" or "jokes" that he or she tells to the live audience. Regardless, the students enjoyed the seminars and the course received a good course evaluation.

\section{The Work: Place and Time Dimension}

Figure 3 illustrates this model. It is still being developed. There are several unique technology components that can slot into the model.

For same place and same time we could use Electronic Classroom and Virtual Notebooks to enhance the face-toface instruction, for same place but different time we could use Virtual Notebook as a strategy, for different place but same time we could use Teleconferencing as a strategy, and finally different time and different place can use any of the above technologies for delivery of instruction.

Once defined, institutions and instructors could use this technology model to identify appropriate tools.

\section{Conclusions}

This paper has introduced two models that summarize how one can communicate and inform students involved in distance education. The first model describes the work and the second model introduces the technology dimension. In this context the paper described our experience with synchronous and asynchronous distance education and lists brief advantages and limitations of each of the above strategies from the perspective of both the student and the professor. The second model dealing with technology will be refined in the near future but tentatively it lists tools suitable for each of the four grid elements.

\begin{tabular}{|c|c|c|}
\hline Time & Same & Different \\
\hline Same & $\begin{array}{l}\text { Traditional } \\
\text { classroom using } \\
\text { (eg., Electronic } \\
\text { Class Room \& } \\
\text { Virtual notebook) }\end{array}$ & $\begin{array}{l}\text { Virtual } \\
\text { Notebook } \\
\text { (eg., } \\
\text { Blackboard.com } \\
\text { as WBI) }\end{array}$ \\
\hline Different & $\begin{array}{l}\text { Teleconferencing } \\
\text { (eg., Picture Tel } \\
\text { \& InterWise) }\end{array}$ & All of the above \\
\hline
\end{tabular}

\section{Figure 3: The Technology}

\section{References}

Moore, Michel (1996). Distance Education: A systems view Boston: Massachusetts, Wadsworth Publishing Company.

Zlateva, Burstein (2001): A Web-Based Graduate Certificate for IT Professionals - Design Choices and First Evaluation Results. Proceedings of the 2001 American Society for Engineering Education Annual Conference \& Exposition Copyright 2001, American Society for Engineering Education, 2001

IDDA (1999) Instructional Design for Distance Education, Accessed November 1, 1999 at http://www.reusda.gov/new/programs/distanced/1d2.htm

\section{Biographies}

Vijay Kanabar is a faculty member of Boston University, where he teaches Ecommerce, Web languages, Database Management and Project Management courses. Prof. Kanabar has authored more that 20 papers and 3 books in the areas of Information Systems and has 22 years of teaching experience in both USA and Canada. 